\title{
Erratum
}

\section{Mirogabalin for the management of postherpetic neuralgia: a randomized, double-blind, placebo- controlled phase 3 study in Asian patients: Erratum.}

In the article by Kato et al., which published in the May 2019 issue of $P A I N^{\circledR}$, the authors note that they made an error in Figure 3, noting the mirogabalin dose as 'QD', rather than the correct 'per day'. The corrected figure and caption is shown below:

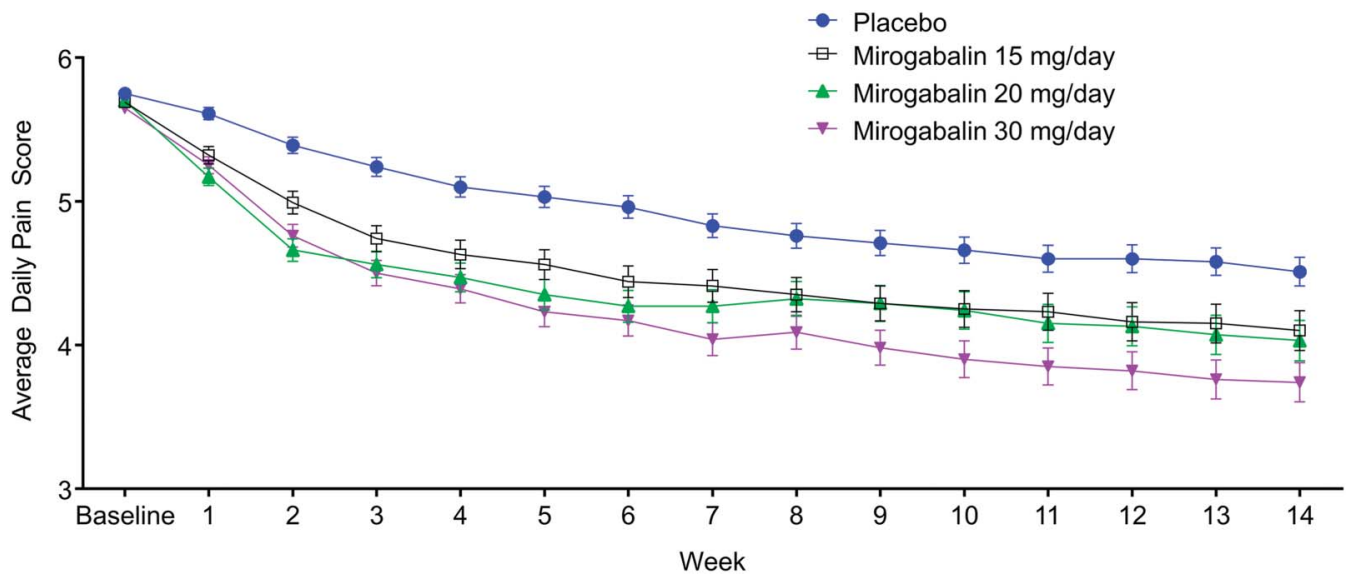

Figure 3. Average daily pain score shown as the time course of the least squares mean with standard error. Data are presented for the modified intent-totreat analysis set. The multiple imputation method was applied using the pattern mixture model with different shift parameters based on reason for discontinuation. The mixed-effect model with repeated measures was performed for the imputed data sets, including treatment, week, and treatmentby-week as fixed effects; week as a repeated measure; and baseline ADPS as a covariate. ADPS, average daily pain score.

The authors apologize for the error.

\section{Reference}

Kato J, Matsui N, Kakehi Y, Murayama E, Ohwada S, Sugihara M. Mirogabalin for the management of postherpetic neuralgia: a randomized, doubleblind, placebo-controlled phase 3 study in Asian patients. PAIN 2019;160:1175-85. 